\title{
Late Spontaneous Posterior Dislocation of Intraocular Lens (IOL) - Case Report
}

\author{
Doongerwala $^{1}$ and Ukti Vora ${ }^{2 *}$ \\ ${ }^{1}$ Department of ophthalmology, Retina Clinic, India \\ ${ }^{2}$ Department of ophthalmology, Lotus College of Optometry, USA
}

*Corresponding author: Ukti Vora, Department of ophthalmology, Lotus College of Optometry, 201, S 4th St, Apt \#605, San Jose-95112. CA, USA

Submission: 監 February 12, 2018; Published: 監 March 27, 2018

\section{Introduction}

Cataract surgeries have undergone a great evolution over a period of time. This evolution helped in reducing the overall rate of spontaneous dislocation of Intra Ocular Lens (IOL) and provide a standard management for cataracts. Until in recent times, cases have been reported with spontaneous dislocation of IOL. This spontaneous dislocation of the intra ocular lens (IOL) with intact capsular bag can be typically seen in conditions resulting from zonular insufficiency and zonulysis [1]. This has usually been associated with conditions like, posterior capsular rent, post ND: YAG laser, trauma, pseudo exfoliation, myopia and other risk factors [2-5]. Although, IOL dislocation can occasionally occur in a spontaneous manner without any predisposing factors [5-10].

The following is a rare case of late spontaneous posterior dislocation of IOL in the vitreous chamber without any predisposing factors and its management.

\section{Case Report}

A 54yr old female visited the clinic with a sudden painless diminished vision in the right eye. She had noticed the loss in her vision since a day. At the time of preliminary examination, she presented the history of both eyes being pseudo aphakic. She was operated for cataract about 3-4 years back without any surgical complications and had complete visual recovery post-surgery. On further inquiry she reported negative history of any ocular trauma, foreign body, anterior or posterior ocular disease and/or any kind of stress to the eye. She reported being on systemic treatment for hypertension for the past 10 years with no history of any other systemic ailments like diabetes, thyroid or heart problems. At this time of evaluation, patient did not present any previous postsurgical records to verify her visual or surgical history.

On ocular assessment her aided visual acuity in the right eye was finger counting at $1 \mathrm{ft},<\mathrm{N} 36$ for reading, while Left eye had an aided visual acuity of 6/9, N6 for near. Retinoscopy in the right eye had a dull hyperopic glow (as seen in aphakic eye of approx $+10.00 \mathrm{DS}$ ), Left eye showed a good glow (approx $-0.75^{*} 100$ ). The intra-ocular pressure (Applanation method) was measured to be
Right Eye - 24mm of $\mathrm{Hg}$ and Left eye - $20 \mathrm{~mm}$ of $\mathrm{Hg}$ at 6:30pm. During the anterior segment evaluation the right eye presented clear cornea, no signs of cell or flare in the anterior chamber but there was no presence of the lens, thus was documented as aphakic. While the left eye was completed within the normal limits and was pseudo aphakic. On further evaluation of the posterior chamber, the right eye reported normal appearance of the disc, blood vessels, macula along with IOL intact the capsular bag within the vitreous humour (Figure $1 \& 2$ ). Left eye reported the posterior segment completely within normal limits. This case was diagnosed as a? late spontaneous posterior dislocation of the IOL with capsular bag in vitreous.

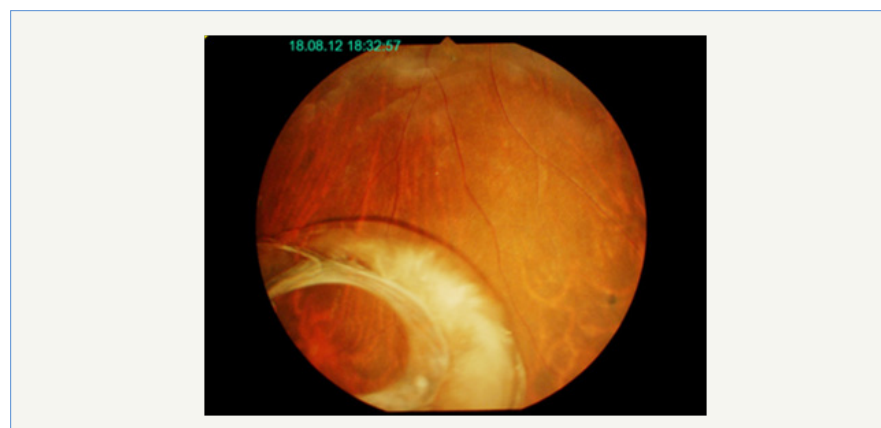

Figure 1: RE - Dislocated IOL with capsular bag in the vitreous

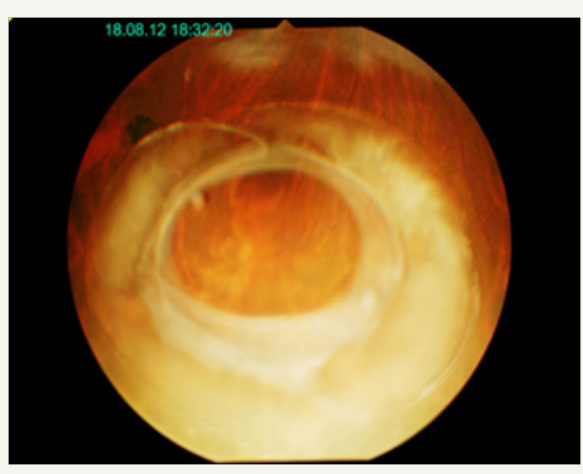

Figure 2: RE - Dislocated IOL with capsular bag in the vitreous 


\section{Case Management}

After complete ocular assessment the patient was started on anti-glaucoma medications (Timolol $0.5 \%$ ) for raised intra ocular pressure. She was then advised and was operated for the Right eye pars-plana vitrectomy with IOL removal and a scleral fixated IOL was implanted under local anesthesia, under guarded visual prognosis. She underwent an uneventful surgery with a removal of the dislocated IOL with the capsular bag (Figures 3-7).

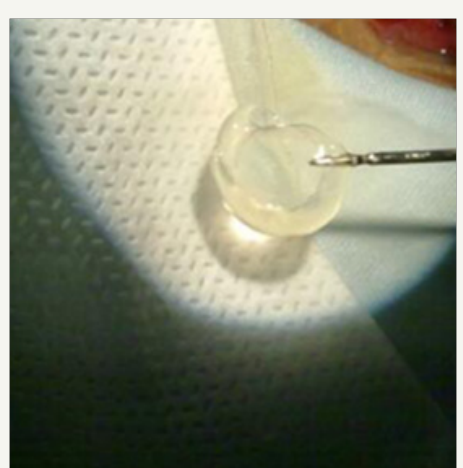

Figure 3: Removal of dislocated IOL with capsular bag

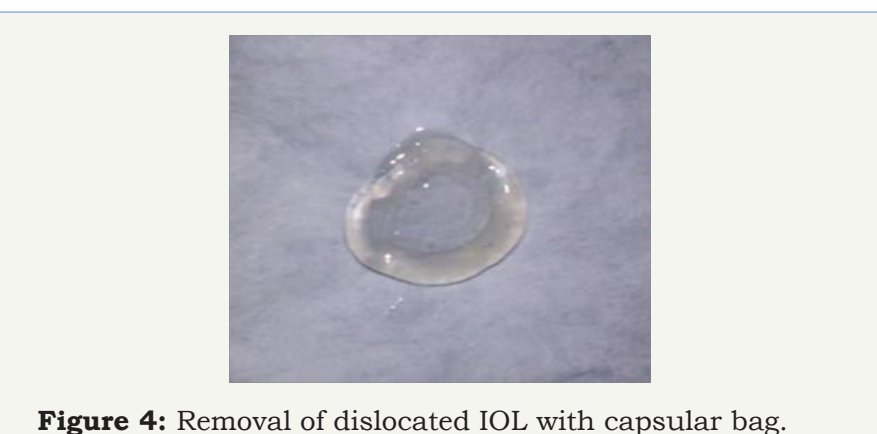

Figure 4: Removal of dislocated IOL with capsular bag.

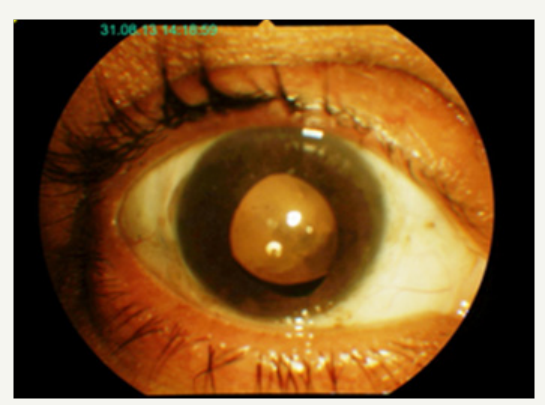

Figure 5: Post surgical images with scleral fixated IOL

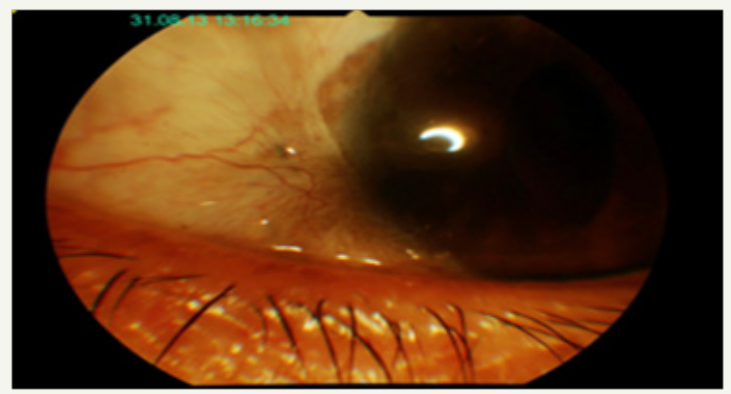

Figure 6: Post surgical images with scleral fixated IOL

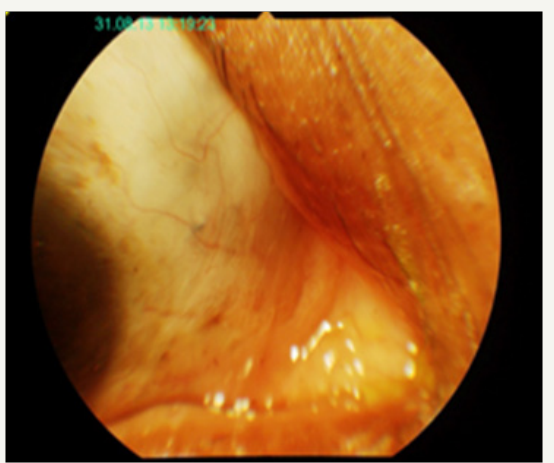

Figure 7: Post surgical images with scleral fixated IOL

Post-surgery her right eye visual acuity improved to $6 / 60$, with pinhole vision of 6/36 and N36(hazy). Anterior segment evaluation showed mild corneal keratitis, along with few cells+ and flare+ in the anterior chamber. The scleral fixated lens was well insitu. The posterior segment had a hazy view due to the corneal inflammation but the disc, blood vessels and the macula appeared to be within normal limits. She was advised topical steroids, antibiotics and anti-inflammatory along with anti-glaucoma medications.

On further follow-ups, corneal inflammation reduced and the medications were gradually tapered. On the final assessment the visual acuity finally improved to 6/24(p), N18(p) with a correction of "- $0.75 /-2.00 * 100$, Add- +2.50 ". The fundus examination showed fine epi-retinal membrane (ERM) on the macula without any pull/ traction and was thus left untreated. This case showed a good postoperative outcome.

\section{Discussion}

Spontaneous dislocation of IOL is usually associated with various predisposing factors (excluding trauma) like; Advanced age, Diabetes mellitus, Pseudo exfoliation, Retinitis pigmentosa, Uveitis, High myopia and Marfan's syndrome. Pseudo exfoliation is known to be the most common cause of IOL dislocation [2-5, 11]. In the absence of these predisposing factors the occurrence of sudden late spontaneous dislocation of an IOL is very rare [12].

Phacoemulsification technique along with continuous curvilinear capsulorhexis and in-the-bag placement of the IOL represents the current standard of care for cataract surgery. Capsulorhexis has been hugely successful in phacoemulsification, allowing a successful IOL implantation. Although, the technique is widely used is does not come without complications. It is reported that the capsular shrinkage being the short term while dislocation of the capsular bag-IOL complex is the long term complications [13]. "Late spontaneous in-the-bag IOL dislocation" is described as a potential complication of cataract surgery in which an IOL that is properly placed within the capsular bag (with or without a capsular tension ring) de-centers many years after uneventful surgery [14].

Therefore, it is important to have mentioned the terms-late, spontaneous and in-the-bag fixation of the IOL fulfil to establish the diagnosis without any other known predisposing factors [15]. In the absence of the predisposing factors the other probable cause 
of this condition rarely could be 'Capsular contraction syndrome'. When it comes to the role of Capsular contraction syndrome, it is important to know without any predisposing factors; late in-thebag dislocation was virtually unreported before the popularization of capsulorhexis [12]. After the arrival and popularity of the phacoemulsification these cases are more frequently reported, thus the technique can be associated to Capsular contraction syndrome [6-10].

Capsular contraction syndrome - is described as a spontaneous reduction of the anterior capsular opening caused due to the metaplasia of the residual epithelial cells and interruption of the zonular support [16]. The use of high vacuum, aspiration and irrigation pressure during phacoemulsification, may provoke zonular injury causing IOL dislocation as a long term complication of an uneventful surgery [15]. Capsular contractions are more frequently observed in cases of smaller capsulorhexis compared to larger capsulorhexis. Unbalance between the centrifugal and centripetal forces of the capsular bag during the phacoemulsification technique may cause rupture/weakening of the zonules [17-19].

Other factors influencing fibrosis and capsular contraction are, type and size of the capsulotomy, type of lens fixation, design and the material of the IOL [16]. Though patients with any type of IOLs are at the risk of IOL dislocation, one-piece PMMA lens with rigid hap tics are known to resist this capsular contraction as compared to flexible hap tics [20].

The best surgical management of these cases is debatable and can differ based on individual cases. Most of the surgical techniques used in these cases are able to give desirable outcomes with low rate of post- surgical complications [13]. The commonly used surgical methods to replace the dislocated IOLs are; scleral fixated IOL, angle-supported anterior chamber IOL, sulcus repositioning and posterior chamber iris sutured IOL. Scleral fixated IOL is known to be the most commonly used surgical technique and was also used in our case presenting good post-surgical prognosis [13].

Though in our case we had to explant and replace the IOL due to the complete dislocation of the lens. It is agreed that it would be desirable to preserve and reposition the existing dislocated IOL if possible in order to avoid a large corneal wound and minimize surgical trauma and major complications. However, in some advanced dislocations, explantation is the only best alternative [2123].

\section{Conclusion}

The condition in the presented case report was considered to be Capsular contraction syndrome. IOL exchange with a scleral suturefixated IOL was the most suitable treatment in our case resulting in improved visual acuity and low rate of complications postsurgery. Lately, with increase in the reports of the bag dislocation of the IOL, it's important to consider the predisposing factors before the cataract surgery for better post-surgical outcomes. Special monitoring must be done while using phacoemulsification technique towards capsule polishing and zonular damage to avoid long term complications in cataract surgeries.

\section{References}

1. Davis D, Brubaker J, Espander L, Stringham J, Crandall A, et.al (2009) Late In-the-Bag Spontaneous Intraocular Lens Dislocation: Evaluation of 86 Consecutive Cases. J Ophthalmology 116(4): 664-670.

2. Smiddy WE, Ibanez GV, Alfonso E, Flynn HW (1995) Surgical management of dislocated lenses. J Cataract Refract Surg 21(1): 64-69.

3. Carlson AN, Stewart WC, Tso PC (1998) Intraocular lens complications requiring removal or exchange. Surv Opthalmol 42(5): 417-440.

4. Tuft SJ, Talks SJ (1998) Delayed dislocation of foldable plate-haptic silicone lenses after Nd: YAG laser anterior capsulotomy. Am J Ophthalmol 126(4): 586-588.

5. Petersen AM, Bluth LL, Campion M (2000) Delayed posterior dislocation of silicone plate-haptic lenses after neodymium: yag capsulotomy. J Cataract Refract Surg 26(12): 1827-1829.

6. Nishi O, Nishi K, Sakanishi K, Yamada Y (1996) Explantation of endocapsular posterior chamber lens after spontaneous posterior dislocation. J Cataract Refract Surg 22(2): 272-275.

7. Zech JC, Tanniére P, Denis P, Trepsat C (1999) Posterior chamber intraocular lens dislocation with the bag. J Cataract Refract Surg 25(8): 11681169.

8. Shigeeda T, Nagahara M, Kato S, Kunimatsu S, Kaji Y, et al (2002) Spontaneous posterior dislocation of intraocular lenses fixated in the capsular bag. J Cataract Refract Surg 28(9): 1689-1693.

9. Tsilou E, Rubin BI, Abraham FA, Kaiser-Kupfer M (2004) Bilateral late posterior chamber intraocular dislocation with the capsular bag in a patient with gyrate atrophy. J Cataract Refract Surg 30(7): 1593-1594.

10. Jehan FS, Mamalis N, Crandall AS (2001) Spontaneous late dislocation of intraocular lens within the capsular bag in pseudoexfoliation patients. Ophthalmology 108(10): 1727-1731.

11. Lorente R \& De Rojas V (2008) Luxación tardía del complejo saco capsular y lente intraocular. In: LorenteR, Mendicute J eds. Cirugía del cristalino. Ponencia Oficial de la Sociedad Española de Oftalmología 2: 17511767.

12. Werner L, Zaugg B, Neuhann T, Burrow M, Tetz M (2012) In the bag capsular tension ring and intraocular lens subluxation or dislocation: A series of 23 cases. Ophthalmology 119(2): 266-271.

13. R Lorente, MV de Rojas, P Vazquez de Parga, Moreno C, Landaluce ML, et al (2010) Management of late spontaneous in-the-bag intraocular lens dislocation: a retrospective analysis of 45 cases. J Cataract Refract Surg 36(8): 1270-1282.

14. Hayashi K, Hirata A, Hayashi H (2007) Possible predisposing factors for in-the-bag and out-of-the-bag intraocular lens dislocation and outcomes of intraocular lens exchange surgery. Ophthalmology 114(5): 969-975.

15. Assia EI, Apple DJ, Morgan RC, Legler UF, Brown SJ (1991) The relationship between the stretching capability of the anterior capsule and zonules. Invest Ophthalmol Vis Sci 32(10): 2835-2839.

16. Gross JG, Kokame GT, Weinberg DV (2004) Dislocated in-the-bag intraocular lens study group. In-the-bag intraocular lens dislocation. Am J Ophthalmol 137(4): 630-635.

17. Coelho RP, Zanatto MC, Paula JS, Romão E (2005) Spontaneous late inthe-bag intraocular lens dislocation after can-opener capsulotomy: case report. Arq Bras Oftalmol 68(6): 864-866.

18. Eagle RCJ, Spencer WT (1996) Lens. In: Spencer WH (Ed.), Ophthalmic pathology: an atlas and textbook. $\left(4^{\text {th }} e d n\right)$, WB Saunders, Philadelphia, USA, pp. 394.

19. Joo CK, Shin JA, Kim JH (1996) Capsular opening contraction after continuous curvilinear capsulorhexis and intraocular lens implantation. J Cataract Refract Surg 22(5): 585-590. 
20. Hayashi K, Hayashi H, Nakao F, Hayashi F (1998) Comparison of decentration and tilt between one piece and three piece polymethyl methacrylate intraocular lenses. Br J Ophthalmol 82(4): 419-422.

21. Jakobsson G, Zetterberg M, Lundstrom M, Stenevi U, Grenmark R, et.al (2010) Late dislocation of in-the-bag and out-of-the bag intraocular lenses: ocular and surgical characteristics and time to lens repositioning. J Cataract Refract Surg 36(10): 1637-1644.
22. Mello MO, Scott IU, Smiddy WE, Flynn HW, Feuer W (2000) Surgical management and outcomes of dislocated intraocular lenses. Ophthalmology 107(1): 62-67.

23. Chan CC, Crandall AS, Ahmed II (2006) Ab externo scleral suture loop fixation for posterior chamber intraocular lens decentration: clinical results. J Cataract Refract Surg 32(1): 121-128.

\section{Medical \& Surgical Ophthalmology Research}

\section{Benefits of Publishing with us}

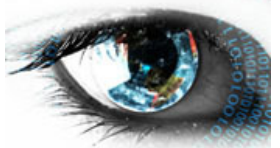

- High-level peer review and editorial services

- Freely accessible online immediately upon publication

- Authors retain the copyright to their work

- Licensing it under a Creative Commons license

- Visibility through different online platforms 